\title{
The Consequence of Complete Dentures on Quality of Life of Edentulous Patients in the South-Indian Population Based on Educational and Socioeconomic Grades
}

Madhan Seenivasan ${ }^{1}$, Fathima Banu ${ }^{2}$, Athiban Inbarajan ${ }^{1}$, Parthasarathy Natarajan ${ }^{1}$, Shanmuganathan Natarajan ${ }^{1}$, Anand Kumar $\mathrm{V}^{2}$, Karthigeyan ${ }^{1}$

1. Prosthodontics, Sri Ramachandra University, Chennai, IND 2. Prosthodontics, Faculty of Dental Sciences, Sri Ramachandra Institute of Higher Education and Research, Chennai, IND

Corresponding author: Fathima Banu, drfathimabanu@yahoo.com

\section{Abstract \\ Purpose}

The purpose of this study was to establish the level of denture satisfaction with socio-demographic variables and educational status of the patients rehabilitated with complete denture.

\section{Materials and method}

A total number of 250 completely edentulous patients were selected who fulfilled the inclusion and exclusion criteria. The patients had no past medical history which affects the oral condition; they were firsttime denture wearers with period of edentulousness altering between six months to one year and were in the age group of 40-50 years, and were willingly involved in the study. The subjects were grouped according to their socioeconomic status such as employment, education and income level. The correlations were statistically determined using regression analysis.

\section{Results}

Statistical analysis was done using Statistical Package for Social Sciences (SPSS, Chicago, Illinois, USA), version 16.0. The significance of percentage error of the two groups was tested by Student $t$ test and $p$ value denoted level of significance ( $p<.05)$. Based on the education level, 30.47\% of the population were under primary level of education, $57.82 \%$ completed higher secondary education and $11.72 \%$ of the population were graduates. Based on employment status, $53.12 \%$ of the population was unemployed, 32.03\% were employed while $14.84 \%$ of the population were pensioners. Based on income per month, the population was classified as $6.25 \%, 31.25 \%, 21.09 \%, 22.66 \%, 18.75 \%$ for no income, less than $3000,5000,8000$ and more than 10000 respectively. Psychological comfort, social ability, and functional improvement was better with higher secondary education level, employed and lower income individuals.

Received 01/23/2020

Review began 02/02/2020 Review ended 02/06/2020 Published 02/09/2020

\section{๑) Copyright 2020}

Seenivasan et al. This is an open access article distributed under the terms of the Creative Commons Attribution License CC-BY 4.0., which permits unrestricted use, distribution, and reproduction in any medium, provided the original author and source are credited.

\section{Conclusion}

Rehabilitation of an elderly individual not only includes clinician skills but also the personal perception by the patient. The study concludes that the though there was no statistically significant difference, the individual with secondary level of education and with employed low socioeconomic status had better denture satisfaction than the other category.

Categories: Quality Improvement, Public Health, Dentistry

Keywords: complete denture satisfaction, socioeconomic status, education level, psychology, edentulism, quality of life, complete denture

\section{Introduction}

Management of edentulous patients during rehabilitation with complete dentures is still lacking with respect to patients based on educational level and socioeconomic status [1]. The need for thought of oral health-related quality of life (QoL) has been increasingly accepted over the last decades, and many studies highlight the psychosocial impacts of oral conditions. This study is based on considerations in making of complete dentures of different socio-demographic variables such as age, gender, literacy level, socioeconomic and educational status may affect satisfaction towards dentures. To assess this, a consistent questionnaire that included questions from domains such as mastication, appearance, speech, comfort, health, denture care and social status is used to establish level of denture satisfaction with sociodemographic variables and educational status of the patients.

The removable denture prosthesis (RDP) must be able to restore the chewing function, aesthetics and 
phonetics to compensate partial edentulism [2]. Considering the biomechanics involved allows the specialist to design a removable partial denture prosthesis by establishing and maintaining lift, stabilization and retention termed the Housset triad. With these imperatives taken into account, and depending on the number of teeth lost and the type of edentulous areas bounded by remaining teeth or without posterior tooth support, the constraints on the prosthesis will be different and functional rehabilitation altered. One such method is by measuring food bolus granulometry before swallowing, associated with analysis of the kinematic parameters developed to distinguish patients with normal mastication from those with badly impaired mastication [3]. Impaired chewing function leads to raise of food bolus particle size, measured by the median particle size of the food bolus at swallowing. It has been revealed that adults with impaired mastication could be distinguished from those with normal function if the median particle size of the bolus that they produced, when chewing raw carrot reached a cut-off value of $4 \mathrm{~mm}$, called the masticatory normative indicator (MNI) [4]. The adjustment of chewing behaviour to food hardness can also characterize healthy mastication. Adaptation to increasing food hardness marks in an augmented number of chewing cycles and an increase in the chewing sequence duration, with no modification of the chewing frequency (number of cycles per second) in healthy subjects $[5,6]$. The mean chewing frequency is slowed down in subjects with chewing deficiencies while eating any type of resistant food. Earlier studies on the chewing ability of dentally impaired subjects showed that a decrease in the number of functionally paired teeth and oral rehabilitation with removable dentures were linked to a decreased masticatory values $[7,8]$. But, the physiological impact of RDP rehabilitation has been seldom studied. Also, the objective of this work was to estimate the impact of partial edentulous areas rehabilitation by removable partial denture prosthesis with a socioeconomic and educational point of view.

Beside the therapist's ability and the quality of dentures, individual factors connected with the patient are very important for the final satisfaction with dentures. Patients are sometimes not satisfied with the constructions which are best, according to the therapist's judgment. Satisfaction with dentures seems to have multiclausal character. According to the results of Frank's studies, the most frequent areas of dissatisfaction were as follows: fit (33.6\%), mastication (29.5\%), natural tooth problems (26.3\%), overall perception (26,2\%), oral cleanliness (20.4\%), speech (17.9\%), appearance (17.8\%), denture cleanliness (15.3\%) and odour (13.2\%) [9,10]. In different studies concerning satisfaction or dissatisfaction with partial removable dentures, more concern was placed on upper partial dentures. Dentists consider dentures to be successful when they meet certain methodological standards, whereas patients assess them from the viewpoint of personal satisfaction. The capability to adapt to new dentures will usually reduce in proportion to the individual status. To assess this, a consistent questionnaire that included questions from domains such as mastication, appearance, speech, comfort, health, denture care and social status was used to determine level of denture satisfaction with socio-demographic variables of completely edentulous patients rehabilitated with prosthesis.

\section{Materials And Methods}

The study was conducted at the Department of Prosthodontics, Sri Ramachandra Institute of Higher Education and Research (SRIHER) with the approval of the ethics committee. A total number of 250 completely edentulous patients were selected who fulfilled the inclusion and exclusion criteria. The patients had no past medical history which affects the oral condition, first-time denture wearers, period of edentulousness altering between six months to one year and Class I edentulous state as classified by American College of Prosthodontics and in the age group of 40-50 years who were willingly involved in the study was selected. The subjects were grouped according to their socioeconomic status such as employment, education and income level. According to the employment level, they were divided into Employed, SelfEmployed, Unemployed and Pensioners. According to education level, they were separated as Primary (till standard five), Secondary (till standard nine), and Tertiary education. Income level they are divided into low, middle, and high-income group. The removable prosthesis was fabricated in the Department of Prosthodontics and their quality were assessed based on the method given by Sato et al [11]. The patients were interviewed at 2-3 months post-treatment. A single person conducted all the questionnaire surveys to reduce the discrepancy. A standardized questionnaire, with 19 questions based on denture satisfaction level and masticatory capacity in the domains of Functional limitation, Psychological discomfort, Psychological disability, and Social disability was administered [12]. All the questions were calculated in scale of satisfied, moderately satisfied and hardly ever. The denture satisfaction questions were only asked at the posttreatment interview and relevant to the satisfaction of their new maxillary/mandibular complete dentures the patients received according to the Likert scale. Statistical analysis was done using Statistical Package for Social Sciences (SPSS, Chicago, Illinois, USA), version 16.0. Significance of percentage error of two groups was tested by Student $t$ test and $p$ value denoted level of significance $(\mathrm{p}<.05)$.

\section{Results}

\section{Distribution of sample}

Based on the education level, $30.47 \%$ of the population were under primary level of education, $57.82 \%$ of the population have done higher secondary education and $11.72 \%$ of the population were graduates. Based on employment status, $53.12 \%$ of population was unemployed, $32.03 \%$ of the population were employed while $14.84 \%$ of the population were pensioners. Based on income per month population were classified as $6.25 \%$, $31.25 \%, 21.09 \%, 22.66 \%, 18.75 \%$ for no income, less than 3000, 5000, 8000 and more than 10000 


\section{Cureus}

respectively.

\section{Psychological discomfort}

On postoperative evaluation based on education, the satisfactory level for psychological comfort was higher for higher secondary educated persons followed by primary education and graduate persons. The distribution of sample was Higher secondary - 41, primary - 22 and graduate - 8 for satisfaction level questionnaire (SAQ)4 and SAQ5, Higher secondary - 55, primary - 29 and graduate - 10 for SAQ9. Based on masticatory ability, the distribution of sample was Higher secondary - 42, primary - 20 and graduate - 2 for masticatory ability questionnaire (MCQ) 9 and Higher secondary - 56, primary - 24 and graduate - 12 for MCQ12. Though there was no statistical significance, the psychological comfort was better with Higher secondary education level (Table 1).

\begin{tabular}{|c|c|c|c|c|c|}
\hline Questionnaire & Education level & Satisfied & Moderately Satisfied & Not Satisfied & Pearson Chi-Square $\mathbf{P}$ value \\
\hline \multirow{3}{*}{ SAQ4 } & Primary & 22 & 10 & 1 & \multirow{3}{*}{0.119659} \\
\hline & Higher Secondary & 41 & 15 & 17 & \\
\hline & Graduate & 8 & 3 & 4 & \\
\hline \multirow{3}{*}{ SAQ5 } & Primary & 21 & 10 & 2 & \multirow{3}{*}{0.105918} \\
\hline & Higher Secondary & 44 & 12 & 18 & \\
\hline & Graduate & 8 & 5 & 2 & \\
\hline \multirow{3}{*}{ SAQ9 } & Prımary & 29 & 2 & 2 & \multirow{3}{*}{0.066393} \\
\hline & Higher Secondary & 55 & 9 & 10 & \\
\hline & Graduate & 10 & 0 & 5 & \\
\hline \multirow{3}{*}{ MCQ9 } & Primary & 20 & 13 & 0 & \multirow{3}{*}{0.818271} \\
\hline & Higher Secondary & 42 & 30 & 2 & \\
\hline & Graduate & 8 & 7 & 0 & \\
\hline \multirow{3}{*}{ MCQ 12} & Primary & 24 & 8 & 1 & \multirow{3}{*}{0.867339} \\
\hline & Higher Secondary & 56 & 16 & 2 & \\
\hline & Graduate & 12 & 2 & 1 & \\
\hline
\end{tabular}

\section{TABLE 1: Psychological Discomfort Based on Education}

SAQ - Satisfaction level questionnaire, MCQ - Masticatory ability questionnaire

On postoperative evaluation based on employment status, the satisfactory level for psychological comfort was more for employed persons followed by unemployed and pensioner persons. The distribution of sample was Employed - 47, Unemployed - 16 and Pensioner - 10 for SAQ4 and Employed-50, Unemployed - 15 and Pensioner - 12 for SAQ5, Employed - 68, Unemployed - 18 and Pensioner - 13 for SAQ9. Based on masticatory ability, the distribution of sample was Employed - 49, Unemployed - 15 and Pensioner - 9 for MCQ9 and Employed-61, Unemployed - 19 and Pensioner - 16 for MCQ12. Though there was no statistical significance, the psychological comfort was better with employed persons (Table 2). 


\section{Cureus}

\begin{tabular}{|c|c|c|c|c|c|}
\hline Questionnaire & Employment Status & Satisfied & Moderately Satisfied & Not Satisfied & Pearson Chi-Square $\mathbf{P}$ value \\
\hline \multirow{3}{*}{ SAQ4 } & Unemployed & 16 & 4 & 5 & \multirow{3}{*}{0.818145} \\
\hline & Employed & 47 & 21 & 14 & \\
\hline & Pensioner & 10 & 6 & 3 & \\
\hline \multirow{3}{*}{ SAQ5 } & Unemployed & 15 & 6 & 4 & \multirow{3}{*}{0.518909} \\
\hline & Employed & 50 & 16 & 17 & \\
\hline & Pensioner & 12 & 6 & 1 & \\
\hline \multirow{3}{*}{ SAQ9 } & Unemployed & 18 & 2 & 5 & \multirow{3}{*}{0.538068} \\
\hline & Employed & 68 & 7 & 8 & \\
\hline & Pensioner & 13 & 2 & 4 & \\
\hline \multirow{3}{*}{ MCQ9 } & Unemployed & 15 & 10 & 0 & \multirow{3}{*}{0.696123} \\
\hline & Employed & 49 & 32 & 2 & \\
\hline & Pensioner & 9 & 10 & 0 & \\
\hline \multirow{3}{*}{ MCQ12 } & Unemployed & 19 & 6 & 0 & \multirow{3}{*}{0.605909} \\
\hline & Employed & 61 & 18 & 4 & \\
\hline & Pensioner & 16 & 3 & 0 & \\
\hline
\end{tabular}

\section{TABLE 2: Psychological Discomfort Based on Employment}

$S A Q$ - Satisfaction level questionnaire, MCQ - Masticatory ability questionnaire

On postoperative evaluation based on income, the satisfactory stage for psychological comfort were higher for low income individuals followed by upper middle class, lower middle class and higher class individuals. The distribution of sample was lower class -25 , upper middle class -17 , lower middle class- 16 and higher class - 13 for SAQ4 and lower class -25, upper middle class - -17 , lower middle class-19 and higher class 12 for SAQ5, lower class -34, upper middle class -25, lower middle class-18 and higher class - 17 for SAQ9. Based on masticatory ability, the distribution of sample was lower class -23 , upper middle class -19 , lower middle class-14 and higher class - 14 for MCO9 and lower class -29, upper middle class -20, lower middle class-21 and higher class - 21 for MCQ12. Although there was no statistical significance, the psychological comfort was more with lower income individual, while it was very less with no income particpants (Table 3). 


\section{Cureus}

\begin{tabular}{|c|c|c|c|c|c|}
\hline Questionnaire & Income per month & Satisfied & Moderately Satisfied & Not Satisfied & Pearson Chi-Square $\mathrm{P}$ value \\
\hline \multirow{5}{*}{ SAQ4 } & Nil & 0 & 0 & 1 & \multirow{5}{*}{0.306507} \\
\hline & 3000 & 25 & 11 & 4 & \\
\hline & 5000 & 16 & 7 & 4 & \\
\hline & 8000 & 17 & 7 & 4 & \\
\hline & 10000\&above & 13 & 4 & 7 & \\
\hline \multirow{5}{*}{ SAQ5 } & Nil & 0 & 0 & 1 & \multirow{5}{*}{0.342548} \\
\hline & 3000 & 25 & 9 & 6 & \\
\hline & 5000 & 17 & 5 & 5 & \\
\hline & 8000 & 19 & 8 & 2 & \\
\hline & 10000\&above & 12 & 6 & 6 & \\
\hline \multirow{5}{*}{ SAQ9 } & Nil & 1 & 0 & 0 & \multirow{5}{*}{0.150084} \\
\hline & 3000 & 34 & 2 & 4 & \\
\hline & 5000 & 18 & 6 & 3 & \\
\hline & 8000 & 25 & 2 & 2 & \\
\hline & 10000\&above & 17 & 1 & 6 & \\
\hline \multirow{5}{*}{ MCQ9 } & Nil & 0 & 1 & 1 & \multirow{5}{*}{0.649235} \\
\hline & 3000 & 23 & 17 & 0 & \\
\hline & 5000 & 14 & 13 & 2 & \\
\hline & 8000 & 19 & 10 & 1 & \\
\hline & 10000\&above & 14 & 10 & 1 & \\
\hline \multirow{5}{*}{ MCQ12 } & Nil & 1 & 0 & 0 & \multirow{5}{*}{0.847432} \\
\hline & 3000 & 29 & 10 & 1 & \\
\hline & 5000 & 21 & 6 & 0 & \\
\hline & 8000 & 20 & 8 & 1 & \\
\hline & 10000\&above & 21 & 3 & 0 & \\
\hline
\end{tabular}

\section{TABLE 3: Psycological Discomfort Based on Income}

$S A Q$ - Satisfaction level questionnaire, MCQ - Masticatory ability questionnaire

\section{Social disability}

On postoperative evaluation based on education, the satisfactory stage for social ability were higher for Higher secondary educated individuals followed by primary education and graduate individuals. The distribution of sample was Higher secondary-49, primary - 25 and graduate - 9 for SAQ3, Higher secondary51 , primary - 23 and graduate -8 for SAQ7. Based on masticatory ability, the distribution of sample was Higher secondary-49, primary - 24 and graduate - 12 for MCQ10, Higher secondary-57, primary - 23 and graduate - 13 for MCQ11 and Higher secondary-54, primary - 25 and graduate - 9 for MCQ13. Though there was no statistical significance, the social ability was better with Higher secondary education level (Table 4). 


\section{Cureus}

\begin{tabular}{|c|c|c|c|c|c|}
\hline Questionnaire & Education level & Satisfied & Moderately Satisfied & Not Satisfied & Pearson Chi-Square $\mathbf{P}$ value \\
\hline \multirow{3}{*}{ SAQ3 } & Primary & 25 & 6 & 2 & \multirow{3}{*}{0.564003} \\
\hline & Higher Secondary & 49 & 12 & 13 & \\
\hline & Graduate & 9 & 3 & 3 & \\
\hline \multirow{3}{*}{ SAQ7 } & Primary & 23 & 7 & 3 & \multirow{3}{*}{0.295081} \\
\hline & Higher Secondary & 51 & 12 & 11 & \\
\hline & Graduate & 8 & 2 & 5 & \\
\hline \multirow{3}{*}{ MCQ10 } & Primary & 24 & 8 & 1 & \multirow{3}{*}{0.725246} \\
\hline & Higher Secondary & 49 & 24 & 1 & \\
\hline & Graduate & 12 & 3 & 0 & \\
\hline \multirow{3}{*}{ MCQ11 } & Primary & 23 & 9 & 1 & \multirow{3}{*}{0.532581} \\
\hline & Higher Secondary & 57 & 15 & 2 & \\
\hline & Graduate & 13 & 1 & 1 & \\
\hline \multirow{3}{*}{ MCQ13 } & Primary & 25 & 6 & 1 & \multirow{3}{*}{0.357926} \\
\hline & Higher Secondary & 54 & 18 & 2 & \\
\hline & Graduate & 9 & 4 & 2 & \\
\hline
\end{tabular}

\section{TABLE 4: Social Disability Based on Education}

$\mathrm{SAQ}$ - Satisfaction level questionnaire, MCQ - Masticatory ability questionnaire

On postoperative assessment based on employment status, the satisfactory level for social ability were higher for employed individuals followed by unemployed and pensioner individuals. The distribution of sample was Employed-57, Unemployed - 16 and Pensioner - 13 for SAQ3 and Employed-57, Unemployed - 17 and Pensioner - 12 for SAQ7. Based on masticatory ability, the distribution of sample was Employed-58, Unemployed - 16 and Pensioner -15 for MCQ10, Employed-61, Unemployed - 19 and Pensioner - 17 for MCQ11 and Employed-61, Unemployed - 17 and Pensioner - 15 for MCQ13. Though there was no statistical significance, the social ability was better with employed individuals (Table 5). 


\section{Cureus}

\begin{tabular}{|c|c|c|c|c|c|}
\hline Questionnaire & Employment Status & Satisfied & Moderately Satisfied & Not Satisfied & Pearson Chi-Square $\mathrm{P}$ value \\
\hline \multirow{3}{*}{ SAQ3 } & Unemployed & 16 & 5 & 4 & \multirow{3}{*}{0.94543} \\
\hline & Employed & 57 & 13 & 13 & \\
\hline & Pensioner & 13 & 4 & 2 & \\
\hline \multirow{3}{*}{ SAQ7 } & Unemployed & 17 & 3 & 5 & \multirow{3}{*}{0.869279} \\
\hline & Employed & 57 & 15 & 11 & \\
\hline & Pensioner & 12 & 4 & 3 & \\
\hline \multirow{3}{*}{ MCQ10 } & Unemployed & 16 & 9 & 0 & \multirow{3}{*}{0.682443} \\
\hline & Employed & 58 & 23 & 2 & \\
\hline & Pensioner & 15 & 4 & 0 & \\
\hline \multirow{3}{*}{ MCQ11 } & Unemployed & 19 & 6 & 0 & \multirow{3}{*}{0.438342} \\
\hline & Employed & 61 & 18 & 4 & \\
\hline & Pensioner & 17 & 2 & 0 & \\
\hline \multirow{3}{*}{ MCQ13 } & Unemployed & 17 & 8 & 0 & \multirow{3}{*}{0.567791} \\
\hline & Employed & 61 & 17 & 4 & \\
\hline & Pensioner & 15 & 3 & 1 & \\
\hline
\end{tabular}

\section{TABLE 5: Social Disability Based on Employment}

$\mathrm{SAQ}$ - Satisfaction level questionnaire, MCQ - Masticatory ability questionnaire

On postoperative evaluation based on income, the satisfactory level for social ability were higher for low income individuals followed by upper middle class, lower middle class and higher class individuals. The distribution of sample was lower class -27 , upper middle class -24 , lower middle class-19 and higher class 13 for SAQ3 and lower class -26, upper middle class -24, lower middle class-19 and higher class - 13 for SAQ7. Based on masticatory ability, the distribution of sample was lower class -28 , upper middle class -20 , lower middle class-19 and higher class - 18 for MCQ10, lower class -28, upper middle class -23, lower middle class-20 and higher class - 22 for MCQ11 and lower class -32, upper middle class -24, lower middle class-20 and higher class - 14 for MCQ13. Though there was no statistical significance, the social ability was better with lower income individual, while it was very less with no income individual (Table 6). 


\section{Cureus}

\begin{tabular}{|c|c|c|c|c|c|}
\hline Questionnaire & Income & Satisfied & Moderately Satisfied & Not Satisfied & Pearson Chi-Square $P$ value \\
\hline \multirow{5}{*}{ SAQ 3} & Nil & 0 & 1 & 0 & \multirow{5}{*}{0.062094} \\
\hline & 3000 & 27 & 6 & 7 & \\
\hline & 5000 & 19 & 7 & 1 & \\
\hline & 8000 & 24 & 1 & 4 & \\
\hline & 10000\&above & 13 & 6 & 5 & \\
\hline \multirow{5}{*}{ SAQ 7} & Nil & 0 & 1 & 0 & \multirow{5}{*}{0.112107} \\
\hline & 3000 & 26 & 9 & 5 & \\
\hline & 5000 & 19 & 3 & 5 & \\
\hline & 8000 & 24 & 1 & 4 & \\
\hline & 10000\&above & 13 & 6 & 5 & \\
\hline \multirow{5}{*}{ MCQ 10} & Nil & 0 & 1 & 0 & \multirow{5}{*}{0.535895} \\
\hline & 3000 & 28 & 10 & 2 & \\
\hline & 5000 & 19 & 8 & 0 & \\
\hline & 8000 & 20 & 9 & 0 & \\
\hline & 10000\&above & 18 & 6 & 0 & \\
\hline \multirow{5}{*}{ MCQ 11} & Nil & 0 & 1 & 0 & \multirow{5}{*}{0.316671} \\
\hline & 3000 & 28 & 11 & 1 & \\
\hline & 5000 & 20 & 7 & 0 & \\
\hline & 8000 & 23 & 5 & 1 & \\
\hline & 10000\&above & 22 & 2 & 0 & \\
\hline \multirow{5}{*}{ MCQ 13} & Nil & 0 & 1 & 0 & \multirow{5}{*}{0.220572} \\
\hline & 3000 & 32 & 7 & 1 & \\
\hline & 5000 & 20 & 6 & 1 & \\
\hline & 8000 & 24 & 4 & 1 & \\
\hline & 10000\&above & 14 & 10 & 0 & \\
\hline
\end{tabular}

\section{TABLE 6: Social Disability Based on Income}

SAQ - Satisfaction level questionnaire, MCQ - Masticatory ability questionnaire

\section{Functional limitation}

On postoperative assessment based on education, the satisfactory level for functional improvement was higher for Higher secondary educated individuals followed by primary education and graduate individuals. The distribution of sample was Higher secondary-49, primary - 25 and graduate - 9 for SAQ1, Higher secondary-51, primary - 23 and graduate -8 for SAQ2. Based on masticatory ability, the distribution of sample was Higher secondary-47, primary - 28 and graduate - 10 for MCQ1, Higher secondary-42, primary 21 and graduate -8 for MCQ2, Higher secondary-46, primary - 26 and graduate - 7 for MCQ3, Higher secondary-40, primary - 27 and graduate - 6 for MCQ4, Higher secondary-52, primary - 25 and graduate - 10 for MCQ5, Higher secondary-57, primary - 23 and graduate - 13 for MCQ6 and Higher secondary-46, primary - 23 and graduate - 8 for MCQ7. Though there was no statistical significance, the functional improvement was better with Higher secondary education level (Table 7). 


\section{Cureus}

\begin{tabular}{|c|c|c|c|c|c|}
\hline Questionnaire & Education level & Satisfied & Moderately Satisfied & Not Satisfied & Pearson Chi-Square P value \\
\hline \multirow{3}{*}{ SAQ1 } & Primary & 19 & 7 & 7 & \multirow{3}{*}{0.898575} \\
\hline & Higher Secondary & 40 & 18 & 16 & \\
\hline & Graduate & 10 & 2 & 3 & \\
\hline \multirow{3}{*}{ SAQ2 } & Primary & 22 & 7 & 4 & \multirow{3}{*}{0.819816} \\
\hline & Higher Secondary & 42 & 17 & 15 & \\
\hline & Graduate & 9 & 4 & 2 & \\
\hline \multirow{3}{*}{ MCQ1 } & Primary & 28 & 5 & 2 & \multirow{3}{*}{0.082518} \\
\hline & Higher Secondary & 47 & 27 & 2 & \\
\hline & Graduate & 10 & 5 & 1 & \\
\hline \multirow{3}{*}{ MCQ2 } & Primary & 21 & 11 & 1 & \multirow{3}{*}{0.874791} \\
\hline & Higher Secondary & 42 & 30 & 2 & \\
\hline & Graduate & 8 & 7 & 0 & \\
\hline \multirow{3}{*}{ MCQ3 } & Primary & 26 & 5 & 2 & \multirow{3}{*}{0.136418} \\
\hline & Higher Secondary & 46 & 26 & 2 & \\
\hline & Graduate & 7 & 7 & 1 & \\
\hline \multirow{3}{*}{ MCQ4 } & Primary & 27 & 6 & 0 & \multirow{3}{*}{0.032246} \\
\hline & Higher Secondary & 40 & 31 & 3 & \\
\hline & Graduate & 6 & 8 & 1 & \\
\hline \multirow{3}{*}{ MCQ5 } & Primary & 25 & 8 & 0 & \multirow{3}{*}{0.712573} \\
\hline & Higher Secondary & 52 & 20 & 2 & \\
\hline & Graduate & 10 & 4 & 1 & \\
\hline \multirow{3}{*}{ MCQ6 } & Primary & 23 & 9 & 1 & \multirow{3}{*}{0.019939} \\
\hline & Higher Secondary & 55 & 17 & 2 & \\
\hline & Graduate & 5 & 10 & 0 & \\
\hline \multirow{3}{*}{ MCQ7 } & Primary & 23 & 10 & 0 & \multirow{3}{*}{0.612193} \\
\hline & Higher Secondary & 46 & 26 & 2 & \\
\hline & Graduate & 8 & 6 & 1 & \\
\hline
\end{tabular}

\section{TABLE 7: Functional Limitation Based on Education}

SAQ - Satisfaction level questionnaire, MCQ - Masticatory ability questionnaire

On postoperative assessment based on employment status, the satisfactory level for functional improvement was higher for employed individuals followed by unemployed and pensioner individuals. The distribution of sample was Employed-49, Unemployed - 10 and Pensioner - 13 for SAQ1 and Employed-49, Unemployed 12 and Pensioner - 14 for SAQ2. Based on masticatory ability, the distribution of sample was Employed-56, Unemployed - 19 and Pensioner - 13 for MCQ1, Employed-50, Unemployed - 12 and Pensioner - 11 for MCQ2, Employed-57, Unemployed - 14 and Pensioner -12 for MCQ3, Employed-50, Unemployed - 15 and Pensioner -12 for MCQ4, Employed-60, Unemployed - 18 and Pensioner -13 for MCQ5, Employed-62, Unemployed - 16 and Pensioner -9 for MCQ6 and Employed-54, Unemployed - 17 and Pensioner - 11 for MCQ7. Though there was no statistical significance, the functional improvement was improved with employed individuals (Table 8 ). 


\section{Cureus}

\begin{tabular}{|c|c|c|c|c|c|}
\hline Questionnaire & Employment Status & Satisfied & Moderately Satisfied & Not Satisfied & Pearson Chi-Square P value \\
\hline \multirow{3}{*}{ SAQ1 } & Unemployed & 10 & 9 & 6 & \multirow{3}{*}{0.16965} \\
\hline & Employed & 49 & 14 & 20 & \\
\hline & Pensioner & 13 & 4 & 2 & \\
\hline \multirow{3}{*}{ SAQ2 } & Unemployed & 12 & 10 & 3 & \multirow{3}{*}{0.228617} \\
\hline & Employed & 49 & 18 & 16 & \\
\hline & Pensioner & 14 & 3 & 2 & \\
\hline \multirow{3}{*}{ MCQ1 } & Unemployed & 19 & 6 & 6 & \multirow{3}{*}{0.717146} \\
\hline & Employed & 56 & 27 & 2 & \\
\hline & Pensioner & 13 & 6 & 2 & \\
\hline \multirow{3}{*}{ MCQ2 } & Unemployed & 12 & 12 & 1 & \multirow{3}{*}{0.772695} \\
\hline & Employed & 50 & 31 & 2 & \\
\hline & Pensioner & 11 & 8 & 0 & \\
\hline \multirow{3}{*}{ MCQ3 } & Unemployed & 14 & 11 & 0 & \multirow{3}{*}{0.456581} \\
\hline & Employed & 57 & 22 & 4 & \\
\hline & Pensioner & 12 & 6 & 1 & \\
\hline \multirow{3}{*}{ MCQ4 } & Unemployed & 15 & 10 & 0 & \multirow{3}{*}{0.852958} \\
\hline & Employed & 50 & 30 & 3 & \\
\hline & Pensioner & 12 & 6 & 1 & \\
\hline \multirow{3}{*}{ MCQ5 } & Unemployed & 18 & 7 & 0 & \multirow{3}{*}{0.851833} \\
\hline & Employed & 60 & 21 & 2 & \\
\hline & Pensioner & 13 & 5 & 1 & \\
\hline \multirow{3}{*}{ MCQ6 } & Unemployed & 16 & 9 & 0 & \multirow{3}{*}{0.062266} \\
\hline & Employed & 62 & 18 & 3 & \\
\hline & Pensioner & 9 & 10 & 0 & \\
\hline \multirow{3}{*}{ MCQ7 } & Unemployed & 17 & 8 & 0 & \multirow{3}{*}{0.676367} \\
\hline & Employed & 54 & 26 & 3 & \\
\hline & Pensioner & 11 & 8 & 0 & \\
\hline
\end{tabular}

\section{TABLE 8: Functional Limitation Based on Employment}

$S A Q$ - Satisfaction level questionnaire, MCQ - Masticatory ability questionnaire

On postoperative assessment based on income, the satisfactory level for functional improvement were higher for low income individuals followed by upper middle class, lower middle class and higher class individuals. The distribution of sample was lower income class -30, upper middle class -21, lower middle class-14 and higher class - 8 for SAQ1 and lower class -35 , upper middle class -13 , lower middle class-10 and higher class - 9 for SAQ2. Based on masticatory ability, the distribution of sample was lower class -38, upper middle class -25, lower middle class-13 and higher class - 11 for MCQ1, lower class -36, upper middle class 28 , lower middle class-15 and higher class - 11 for MCQ2, lower class -35 , upper middle class -30, lower middle class-23 and higher class - 7 for MCQ3, lower class -42 , upper middle class -30 , lower middle class-21 and higher class - 10 for MCQ4, lower class -41, upper middle class -20, lower middle class-15 and higher class - 9 for MCQ5, lower class -33, upper middle class -20, lower middle class-15 and higher class - 9 for MCQ6 and lower class -35, upper middle class -17, lower middle class-15 and higher class - 11 for MCQ7. Though there was no statistical significance, the functional improvement was better with lower income 


\section{Cureus}

individual, while it was very less with no income individual (Table 9).

\begin{tabular}{|c|c|c|c|c|c|}
\hline Questionnaire & Income & Satisfied & Moderately Satisfied & Not Satisfied & Pearson Chi-Square $\mathbf{P}$ value \\
\hline \multirow{5}{*}{ SAQ 1} & Nil & 1 & 0 & 1 & \multirow{5}{*}{0.715441} \\
\hline & 3000 & 30 & 15 & 12 & \\
\hline & 5000 & 14 & 3 & 2 & \\
\hline & 8000 & 21 & 10 & 2 & \\
\hline & 10000\&above & 8 & 1 & 0 & \\
\hline \multirow{5}{*}{ SAQ 2} & Nil & 2 & 1 & 1 & \multirow{5}{*}{0.753563} \\
\hline & 3000 & 35 & 27 & 18 & \\
\hline & 5000 & 10 & 2 & 1 & \\
\hline & 8000 & 13 & 1 & 0 & \\
\hline & 10000\&above & 9 & 1 & 2 & \\
\hline \multirow{5}{*}{ MCQ 1} & Nil & 2 & 1 & 1 & \multirow{5}{*}{0.738232} \\
\hline & 3000 & 38 & 18 & 10 & \\
\hline & 5000 & 13 & 10 & 2 & \\
\hline & 8000 & 25 & 11 & 1 & \\
\hline & 10000\&above & 11 & 1 & 1 & \\
\hline \multirow{5}{*}{ MCQ 2} & Nil & 1 & 0 & 1 & \multirow{5}{*}{0.990977} \\
\hline & 3000 & 36 & 23 & 3 & \\
\hline & 5000 & 15 & 10 & 3 & \\
\hline & 8000 & 28 & 20 & 1 & \\
\hline & 10000\&above & 11 & 1 & 0 & \\
\hline \multirow{5}{*}{ MCQ 3} & Nil & 1 & 0 & 1 & \multirow{5}{*}{0.738682} \\
\hline & 3000 & 35 & 9 & 1 & \\
\hline & 5000 & 23 & 13 & 5 & \\
\hline & 8000 & 30 & 13 & 1 & \\
\hline & 10000\&above & 7 & 1 & 0 & \\
\hline \multirow{5}{*}{ MCQ 4} & Nil & 1 & 2 & 1 & \multirow{5}{*}{0.983131} \\
\hline & 3000 & 42 & 18 & 0 & \\
\hline & 5000 & 21 & 10 & 4 & \\
\hline & 8000 & 30 & 10 & 1 & \\
\hline & 10000\&above & 10 & 1 & 0 & \\
\hline \multirow{7}{*}{ MCQ 5} & Nil & 1 & 1 & 0 & \multirow{5}{*}{0.764083} \\
\hline & 3000 & 41 & 10 & 0 & \\
\hline & 5000 & 15 & 18 & 3 & \\
\hline & 8000 & 20 & 4 & 1 & \\
\hline & 10000\&above & 9 & 1 & 0 & \\
\hline & Nil & 3 & 1 & 1 & \\
\hline & 3000 & 33 & 9 & 0 & \\
\hline
\end{tabular}




\section{Cureus}

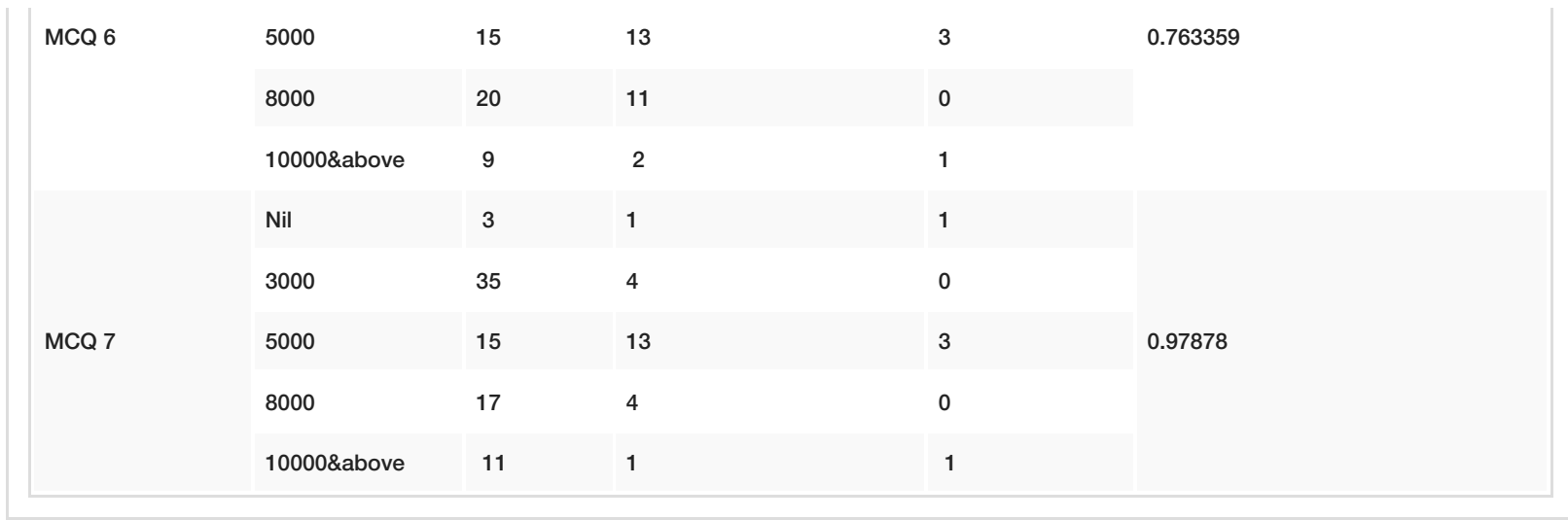

TABLE 9: Functional Limitation Based on Income

$\mathrm{SAQ}$ - Satisfaction level questionnaire, MCQ - Masticatory ability questionnaire

\section{Discussion}

Psychological assessments of patients have been found to be without influence on patients' judgment of dentures, whereas, others have been reported to distinguish significantly between satisfied and dissatisfied denture wearers $[13,14]$. Several studies demonstrated that the patient's judgment can be predicted by information related to patient perceptions, expectations, and prior experiences [15]. Denture quality is defined in relation to a number of areas difficult to assess and no generally accepted standards exist. Accordingly, the validity and reliability of recordings of the quality of complete dentures are often doubtful [16]. Edentulism is considered a handicap with impacts on quality of life and nutrition. Provision of new complete dentures improves oral health-related quality of life. Patient's satisfaction with their dentures is likely to be affected by their ability to perform certain tasks with them [17]. The present study was done to evaluate whether education level and socioeconomic status have an effect on the satisfaction level of the patient. Studies in edentulous subjects strongly support the concept that patient-based measures are more sensitive than functional measures for detecting differences between treatments [18].

The present study revealed that patient satisfaction was better with employed individuals but with the lowincome group compared to the high-income group. In addition, the secondary level of educated individual had better satisfaction. This is contradictory to Poljak-Guberina et al. who found that age, education, marital status, income state, size of the residence and regional affiliation did not have a significant influence on satisfaction of patients with the prosthesis [19]. Also, not wearing prostheses was not linked to neuroticism. On the contrary, some researchers found no relationship between denture satisfaction and personality [20]. However, they used incomprehensive personality tests and paid little attention to reliability, validity, and suitability of the used tests. Moreover, Lowental and Tau found no relation between denture satisfaction and personality found no relationship between denture satisfaction and personality when denture satisfaction was assessed using denture satisfaction questionnaire [21].

\section{Conclusions}

Rehabilitation of an elderly individual not only includes clinician skills but also the personal perception by the patient. The study concludes that though there was no statistically significant difference, the individual with a secondary level of education and with employed low socioeconomic status had a better denture satisfaction than the other categories.

\section{Additional Information}

\section{Disclosures}

Human subjects: Consent was obtained by all participants in this study. Institutional Ethics Committee issued approval IEC-NI/11/OCT/25/26. The ethical approval has been obtained. Animal subjects: All authors have confirmed that this study did not involve animal subjects or tissue. Conflicts of interest: In compliance with the ICMJE uniform disclosure form, all authors declare the following: Payment/services info: All authors have declared that no financial support was received from any organization for the submitted work. Financial relationships: All authors have declared that they have no financial relationships at present or within the previous three years with any organizations that might have an interest in the submitted work. Other relationships: All authors have declared that there are no other relationships or activities that could appear to have influenced the submitted work.

\section{References}


1. Steele JG, Ayatollahi SM, Walls AWG, Murray JJ: Clinical factors related to reported satisfaction with oral function amongst dentate older adults in England. Community Dent Oral Epidemiol. 1997, 25:143-149. 10.1111/j.1600-0528.1997.tb00912.x

2. Leao A, Sheiham A: Relation between clinical dental status and subjective impacts on daily living . J Dent Res. 1995, 74:1408-1413. 10.1177/00220345950740071301

3. Vervoorn JM, Duinkerke AS, Luteijn F, van de Poel AC: Assessment of denture satisfaction. Community Dent Oral Epidemiol. 1988, 16:364-7. 10.1111/j.1600-0528.1988.tb00583.x

4. Ntala PC, Niarchou AP, Polyzois GL, Frangou MJ: Screening of edentulous patients in a dental school population using the prosthodontic diagnostic index. Gerodontology. 2010, 27:114-20. 10.1111/j.17412358.2009.00317.x

5. Locker D, Slade G: Oral health and the quality of life among older adults: the oral healthimpact profile . J Can Dent Assoc. 1993, 59:830-838.

6. Garrett NR, Kapur KK, Perez P: Effects of improvements of poorly fitting dentures and new dentures on patient satisfaction. J Prosthet Dent. 1996, 76:403-413. 10.1016/S0022-3913(96)90546-6

7. Knezovid-Zlatarid D, Čelebid A, Valentid-Peruzovid M, Jerolimov V, Čelid R, Filipovid-Zore I, Alajbeg I: Pacijentova procjena uspješnosti protetske terapije djelomičnim protezama [Article in Croatian] . Acta Stomat Croat. 2000, 34:365-72.

8. Heydecke G, Klemetti E, Awad MA, Lund JP, Feine JS: Relationship between prosthodontic evaluation and patient ratings of mandibular conventional and implant prostheses. Int J Prosthodont. 2003, 16:307-312.

9. Johansson A, Unell L, Johansson AK, Carlsson GE: A 10-year longitudinal study of self-assessed chewing ability and dental status in 50-year-old subjects. Int J Prosthodont. 2007, 20:643-645.

10. Bellini D, Dos Santos MB, De Paula Prisco Da Cunha V, Marchini L: Patients' expectations and satisfaction of complete denture therapy and correlation with locus of control. J Oral Rehabil. 2009, 36:682-686. 10.1111/j.1365-2842.2009.01967.x

11. Sato Y, Hamada S, Akagawa Y, Tsuga K: A method of quantifying overall satisfaction of complete denture patients. J Oral Rehabil. 2000, 27:952-57.

12. Seenivasan M, Banu F, Inbarajan A, Natarajan P, Natarajan S, Anand Kumar V: The effect of complete dentures on the quality of life of edentulous patients in the South Indian population based on gender and systemic disease. Cureus. 2019, 11:e4916. 10.7759/cureus.4916

13. Manne S, Mehra R: Accuracy of perceived treatment needs among geriatric denture wearers . Gerodontology. 1983, 2:67-71. 10.1111/j.1741-2358.1983.tb00240.x

14. Friedman N, Landesman HM, Wexler M: The influences of fear, anxiety, and depression on the patient's adaptive responses to complete dentures. Part I. J Prosthet Dent. 1987, 58:687-9.

15. Baer ML, Elias SA, Reynolds MA: The use of psychological measures in predicting patient satisfaction with complete dentures. Int J Prosthodont. 1992, 5:221-6.

16. Gordon SR: Measurement of oral status and treatment need among subjects with dental prostheses: are the measures less reliable than the prostheses? Part 1: oral status in removable prosthodontics. J Prosthet Dent. 1991, 65:664-8.

17. Awad MA, Lund JP, Shapiro SH, et al.: Oral health status and treatment satisfaction with mandibular implant overdentures and conventional dentures: a randomised clinical trial in a senior population. Int J Prosthodont. 2003, 16:390-396.

18. Frank RP, Brudvik JS, Leroux B, Milgrom P, Hawkins N: Relationship between the standards of removable partial denture construction, clinical acceptability, and patient satisfaction. J Prosthet Dent. 2000, 83:521-7.

19. Poljak-Guberina R, Culig B, Zivković O, Catović A, Kuzmanović D, Muljacić A: Patients' satisfaction with prosthetic devices. Coll Antropol. 2005, 29:615-621.

20. Smith H: Measurement of personality traits and their relation to patient satisfaction with complete dentures. J Prosthet Dent. 1976, 35:492-503.

21. Lowental U, Tau S: Effects of ethnic origin, age and bereavement on complete denture patients . J Prosthet Dent. 1980, 44:133-36. 10.1016/0022-3913(80)90123-7 